\title{
Time to separate MOG-Ab-associated disease from AQP4-Ab-positive neuromyelitis optica spectrum disorder
}

Yael Hacohen, MRCPCH DPhil, and Jacqueline Palace, RFCP

Neurology ${ }^{\circledR}$ 2018;90:947-948. doi:10.1212/WNL.0000000000005619

Antibodies (Abs) against conformational myelin oligodendrocyte glycoprotein (MOG) are a recently well-recognized cause of acquired demyelination. MOG-Abs have been frequently reported in children presenting with acute disseminated encephalomyelitis and optic neuritis but also in adults with neuromyelitis optica spectrum disorder (NMOSD) and its limited forms. ${ }^{1}$ Although MOG-Abs were initially linked to a monophasic presentation, ${ }^{2}$ longer followup times have shown an increasing number of patients with positive MOG-Abs and relapses. ${ }^{3}$ The clinical phenotype of patients with MOG- $\mathrm{Ab}$-associated relapsing disease is different from that of patients with multiple sclerosis (MS) but overlaps that of patients with aquaporin 4 (AQP4)-Ab NMOSD. ${ }^{2,4,5}$ The presence of MOG-Abs is usually associated with better visual and motor outcomes than AQP4-Ab and quicker response to first-line treatments, ${ }^{1}$ although a treatment-resistant group, who relapse on therapeutic doses of rituximab, has been reported. ${ }^{6}$

Earlier studies that looked at Abs to the linear epitopes of the denatured MOG protein using ELISA and Western blotting resulted in inconsistent results and positivity in patients with MS and healthy controls. ${ }^{7}$ In addition, even when the more appropriate cell-based assays were used, there were differences in the sensitivity and specificity, which depended on technical factors. The use of the full-length protein construct increases the sensitivity compared to the truncated form that lacks the intracellular domain, and the use of a better secondary $\mathrm{Ab}^{8}$ increases the specificity compared to some anti-human immunoglobulin $\mathrm{G}$, which appears to cross react with immunoglobulin $\mathrm{M}$ as well. ${ }^{8}$

In this issue of Neurology ${ }^{\circledR}$, Cobo-Calvo et al. ${ }^{9}$ report a large cohort of 197 adult patients with MOG-Abs retrospectively recruited from French referral centers for neuroinflammatory disorders. Of these 197 patients, 139 (70.6\%) were diagnosed at presentation (after 2014, when the assay became available), and 58 (29.4\%), who presented before 2014 , were retrospectively diagnosed. In addition to describing the clinical, paraclinical, and outcomes in patients with MOG-Ab, the authors compared these patients to those with AQP4-Ab-positive NMOSD. As in previous reports and in contrast to patients with AQP4-Abs, MOG-Ab-positive patients were predominantly white (93\%), without a female predominance, and had better outcomes. Optic neuritis was confirmed as the commonest presentation in nonpediatric MOG-Abpositive patients. ${ }^{3}$ Nineteen percent of patients with MOG-Abs and abnormal brain MRI showed imaging features of predominantly cortical gray matter changes, which were also reported by others, ${ }^{10}$ and a clinical phenotype of encephalopathy, seizures, and headaches, together with focal leptomeningeal enhancement. This phenotype could be easily misdiagnosed as primary CNS vasculitis, with both management and treatment implications.

Approximately $45 \%$ of patients with MOG-Abs relapsed over the first 2 years, and this was not different in the incident vs the retrospective cohort. This is lower than in a nonincident cohort from Germany but similar to a UK incident cohort. ${ }^{3}$ There were no differences in the proportion of patients who attained Disability Status Scale score of 3.0 or visual acuity of 0.2 when relapsing patients were compared to monophasic patients, again confirming that most of the

\section{Correspondence}

Dr. Hacohen

y.hacohen@ucl.ac.uk

\section{RELATED ARTICLE}

Clinical spectrum and prognostic value of CNS MOG autoimmunity in adults: The MOGADOR study

Page 952 
disability could be driven by the first attack. ${ }^{3}$ Among cases whose MOG-Ab titers were followed up, the titers were higher at relapse than in remission, but only 2 patients (18.2\%) showed negative conversion, which is comparable to the UK study. ${ }^{3}$ With the use of a live cell-based assay, there were some trends in Ab titers, disease course, and immunosuppression, but the authors noted that on an individualpatient basis, these were not reliable enough to use in the clinical setting to manage patients.

The retrospective design, using nonstandardized imaging protocols and follow-up visits, along with nonrandomized treatment allocations, limits some conclusions, but the findings support, strengthen, and build on previous MOG-Ab studies. Although immunosuppressive agents are generally accepted as effective in preventing relapse in AQP4-Ab-positive NMOSD, the study design was not suitable to assess treatment response and relapse prevention in MOG-Ab-positive patients. Unanswered questions include the long-term risk of relapse in incident cases of MOG-Ab disease, including pediatric-onset cases, and the effect of early relapse prevention. In addition, in patients with relapsing disease, it is not clear what the optimum treatment regimens should be.

Despite the observed predilection for the optic nerve and the spinal cord, ${ }^{9}$ only $19 \%$ of patients fulfilled the International Panel for NMO Diagnosis 2015 criteria for NMOSD, ${ }^{11}$ because those without AQP4-Abs have to fulfill more stringent conditions to be diagnosed with NMOSD such as having dissemination in space with at least one of these affecting a core location, with additional supporting MRI findings. As the authors note, this emphasizes the complexity of classifying patients on the basis of the clinical instead of a biological phenotype. Recent studies looking at the effect of MOG-Abs in both cell culture and mouse models reveal primary demyelination with loss of the microtubule cytoskeleton of oligodendrocytes, resulting in altered expression of axonal proteins. In contrast, AQP4-Ab is a primary astrocytopathy with secondary demyelination and complement activation. ${ }^{12}$ With increased availability of biological treatment (monoclonal Abs) with specific mechanism of action, there is a risk that grouping patients by the clinical syndrome, rather than defining them on the basis of the mechanisms of their disease, may result in treatment failure and exposure to potentially serious side effect. There is now evidence that patients with MOG-Abs have a different disease course, suggesting that they may differ in their response to some treatments compared to patients with AQP4-Abs. Therefore, the recent NMOSD criteria may need revision to take account MOG-Ab disease and its broadening phenotype.

\section{Study funding}

No targeted funding reported.

\section{Disclosure}

Y. Hacohen reports no disclosures. J. Palace has served on the scientific advisory boards of ARGENX and WIRMS; has received speaker honoraria from Merck Serono, Biogen Idec, and Novartis; holds a patent for ISIS Innovation Ltd. to protect for the use of metabolomics as a method to diagnose and stage disease in multiple sclerosis; has been a consultant for Merck Serono, Novartis, Alexion, and MedDay; has received research support from the Multiple Sclerosis Society, Guthy Jackson, Eugene Devic European Network, National Institute for Health Research, ABIDE, and Medical Research Council; and runs a clinical NMO service with MOG-Abpositive patients and has published in this area. Go to Neurology.org/ $\mathrm{N}$ for full disclosures.

\section{References}

1. Reindl M, Jarius S, Rostasy K, Berger T. Myelin oligodendrocyte glycoprotein antibodies: how clinically useful are they? Curr Opin Neurol 2017;30:295-301.

2. Kitley J, Waters P, Vincent A, Palace J. Features of neuromyelitis optica spectrum disorders and aquaporin-4 with myelin-oligodendrocyte glycoprotein antibodies: reply. JAMA Neurol 2014;71:924.

3. Duignan S, Wright S, Rossor T, et al. Myelin oligodendrocyte glycoprotein and aquaporin-4 antibodies are highly specific in children with acquired demyelinating syndromes. Dev Med Child Neurol Epub 2018 Feb 12.

4. Hacohen Y, Mankad K, Chong WK, et al. Diagnostic algorithm for relapsing acquired demyelinating syndromes in children. Neurology 2017;89:269-278.

5. Jurynczyk M, Geraldes R, Probert F, et al. Distinct brain imaging characteristics of autoantibody-mediated CNS conditions and multiple sclerosis. Brain 2017;140: 617-627.

6. Hacohen Y, Wong YY, Lechner C, et al. Disease course and treatment responses in children with relapsing myelin oligodendrocyte glycoprotein antibody-associated disease. JAMA Neurol 2018;75:478-487.

7. O'Connor KC, McLaughlin KA, De Jager PL, et al. Self-antigen tetramers discriminate between myelin autoantibodies to native or denatured protein. Nat Med 2007;13: 211-217.

8. Hennes EM, Baumann M, Schanda K, et al. Prognostic relevance of MOG antibodies in children with an acquired demyelinating syndrome. Neurology 2017;89:900-908.

9. Cobo-Calvo A, Ruiz A, Maillart E, et al. Clinical spectrum and prognostic value of CNS MOG autoimmunity in adults: the MOGADOR study. Neurology 2018;90: e1858-e1869.

10. Ogawa R, Nakashima I, Takahashi T, et al. MOG antibody-positive, benign, unilateral, cerebral cortical encephalitis with epilepsy. Neurol Neuroimmunol Neuroinflamm 2017;4:e322.

11. Wingerchuk DM, Banwell B, Bennett JL, et al. International consensus diagnostic criteria for neuromyelitis optica spectrum disorders. Neurology 2015;85:177-189.

12. Hoftberger R, Lassmann $\mathrm{H}$. Inflammatory demyelinating diseases of the central nervous system. Handb Clin Neurol 2017;145:263-283. 


\section{Neurology}

\section{Time to separate MOG-Ab-associated disease from AQP4-Ab-positive neuromyelitis optica spectrum disorder}

Yael Hacohen and Jacqueline Palace

Neurology 2018;90;947-948 Published Online before print April 25, 2018

DOI 10.1212/WNL.0000000000005619

\section{This information is current as of April 25, 2018}

Updated Information \&

Services

References

Subspecialty Collections

Permissions \& Licensing

Reprints including high resolution figures, can be found at: http://n.neurology.org/content/90/21/947.full

This article cites 11 articles, 3 of which you can access for free at: http://n.neurology.org/content/90/21/947.full\#ref-list-1

This article, along with others on similar topics, appears in the following collection(s):

All Demyelinating disease (CNS)

http://n.neurology.org/cgi/collection/all_demyelinating_disease_cns Devic's syndrome

http://n.neurology.org/cgi/collection/devics_syndrome

Multiple sclerosis

http://n.neurology.org/cgi/collection/multiple_sclerosis

Information about reproducing this article in parts (figures,tables) or in its entirety can be found online at:

http://www.neurology.org/about/about_the_journal\#permissions

Information about ordering reprints can be found online:

http://n.neurology.org/subscribers/advertise

Neurology ${ }^{\circledR}$ is the official journal of the American Academy of Neurology. Published continuously since 1951, it is now a weekly with 48 issues per year. Copyright @ 2018 American Academy of Neurology. All rights reserved. Print ISSN: 0028-3878. Online ISSN: 1526-632X.

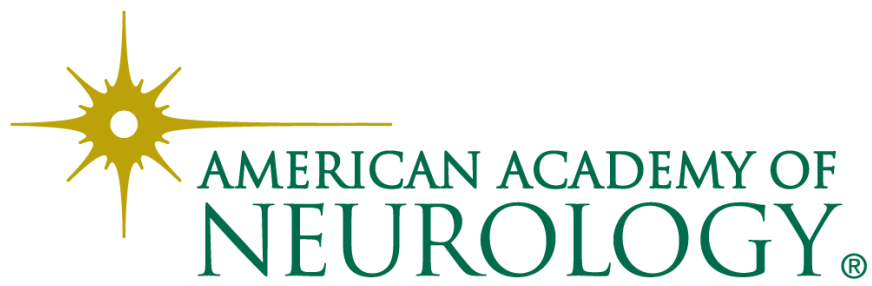

